\title{
Sentiment Analysis of Facebook Users Reacting to Political Campaign Posts
}

RODRIGO SANDOVAL-ALMAZAN, Facultad de Ciencias Políticas y Sociales, Universidad Autonoma del Estado de Mexico, Toluca, Estado de México, Mexico

DAVID VALLE-CRUZ, Rectoria, Universidad Autonoma del Estado de Mexico, Toluca, Estado de México, Mexico

A recent trend in political campaign studies is the use of sentiment analysis to understand users' decisions. The scandal of Facebook and Cambridge Analytics is an example of efforts to use social media platforms to impact citizens' will. This research aims to answer the question: Did the Facebook reactions of users in Mexico reflect the outcomes of the elections and possibly also the users' emotions toward the political candidates of the State of Mexico in 2017? To answer the research question, we analyzed data collected from 4,128 Facebook posts and their reactions. The available reactions for Facebook users are: like, love, haha, wow, sad, and angry. Doing so revealed some kind of mood from the users in the Facebook comments section and opinions of the local government campaign in the central State of Mexico. The elections studied took place in June 2017. Our findings show that the winning political party had more negative sentiment and fewer posts and users' discussions of the candidates in Facebook comments sections than the political party with the largest positive sentiment. This party was unsuccessful in winning the elections.

CCS Concepts: • Information systems $\rightarrow$ Information retrieval; Retrieval tasks and goals; Sentiment analysis;

Additional Key Words and Phrases: Social media, sentiment analysis, reactions, Facebook

ACM Reference format:

Rodrigo Sandoval-Almazan and David Valle-Cruz. 2020. Sentiment Analysis of Facebook Users Reacting to Political Campaign Posts. Digit. Gov.: Res. Pract. 1, 2, Article 12 (April 2020), 13 pages.

https://doi.org/10.1145/3382735

\section{INTRODUCTION}

The digital transformation has changed political campaigns and communication through social media, which has also changed interaction between politicians and citizens. Social media platforms such as Facebook, Twitter, and YouTube have had different impacts on the political sphere. Some scholars expect changes in political participation as well as in online political protest and political campaigns [6, 7, 19, 22, 44, 46]. The use of Facebook in politics has been widely studied: the presidential election, political discourse through Facebook timelines, and voting $[1,8,18,36]$. Technology is in flux, and Facebook changed the "like" button for six emoticons representing reactions that show different emotional states: like, love, haha, wow, sad, and angry. This novelty of going from a

Author's addresses: R. S.-Almazan, Facultad de Ciencias Políticas y Sociales, Universidad Autonoma del Estado de Mexico, Instituto Literario No. 100. Toluca, 50000 México; email: rsandovala@uaemex.mx; D. V.-Cruz, Rectoria, Universidad Autonoma del Estado de Mexico, Instituto Literario No. 100. Toluca, 50000 México; email: davacr@uaemex.mx.

Permission to make digital or hard copies of part or all of this work for personal or classroom use is granted without fee provided that copies are not made or distributed for profit or commercial advantage and that copies bear this notice and the full citation on the first page. Copyrights for third-party components of this work must be honored. For all other uses, contact the owner/author(s).

(c) 2020 Copyright held by the owner/author(s).

2639-0175/2020/04-ART12

https://doi.org/10.1145/3382735

Digital Government: Research and Practice, Vol. 1, No. 2, Article 12. Publication date: April 2020. 
single option to six different alternatives to express various emotional states represents an important expansion for user expression on social media. In political campaigns that use Twitter and Facebook to engage with users, this novelty allows us to study the different moods and emotions of users. This new data provided by Facebook are very useful in determining the preferences and sentiments of social media users. A complementary research path for understanding users' sentiments is to investigate the relation between emotional expression within the Facebook framework during political campaigns supporting candidates and the influence (if any) it has on other users of social media.

Due to the novelty of the use of Facebook emoticons/reactions in political campaigns, there are few studies on this topic. The aim of this article is to fill this gap and increase the understanding of the use of Facebook emoticons/reactions in the context of political campaigns. Our research focuses on studying the sentiment of Facebook users in terms of posts made during a political campaign. To accomplish this goal, our primary research question is: Did the Facebook reactions of users in Mexico reflect the outcomes of the elections and possibly also the users' emotions towards the political candidates of the State of Mexico in 2017?

This study focuses on the use of Facebook emoticons. Electoral behavior is a multi-factor phenomenon that includes social issues, political culture, and political information, among others. Here, we seek to understand one part of this phenomenon through the sentiment analysis of Facebook emoticons/reactions to political campaign posts. Accordingly, our hypotheses are: H1: Facebook emoticons/reactions reflect the emotions of users toward the candidates during the gubernatorial election in the State of Mexico in 2017. H2: Facebook emoticons/reactions may have predicted the outcome of the gubernatorial election in the State of Mexico in 2017.

To test our hypotheses, we collected emojis/reactions generated on Facebook posts from the local government campaign from March to May 2017. Using these data, we analyzed the user sentiments expressed by way of Facebook emojis/reactions. The analysis was done over time and the subjects analyzed were the followers of the four main political parties who had nominated a candidate for election: Partido Revolucionario Institucional (PRI), Partido Acción Nacional (PAN), Partido de la Revolución Democrática (PRD), and Movimiento de Regeneración Nacional (MORENA). The remainder of this article is divided into five sections, starting with this introduction. The second section is a literature review of different Facebook studies on local elections and the use of sentiment analysis; the third section describes our method of data collection and analysis; the fourth section presents findings and discussion. The final section provides the conclusion of the research.

\section{LITERATURE REVIEW}

This section is divided in two subsections. The first section focuses on Facebook and elections, and the second section discusses sentiment analysis using social media.

\subsection{Facebook and Elections}

With different perspectives, information, technical aspects, engagement, and voter perspectives, scholars have provided insights into the use of Facebook (FB). Very few have analyzed the emotional perspective using the emoticons/reactions available to users of this platform. Tian and colleagues suggested that "Facebook reactions are a good data source for such a purpose" [43]. FB reactions, e.g., "Love" and "Anger," indicate the overall sentiment of the person reacting. These scholars investigated the types of emojis/reactions used for comments of different reactions-types: pro/anti. They analyzed $21 \mathrm{~K}$ Facebook posts, $72 \mathrm{M}$ reactions, and $8 \mathrm{M}$ comments from social media across four countries to support this concept.

There are recent studies on the impact of Facebook on elections. Bacallao-Pino [3] reports that the use of Facebook by students during the elections in Chile had two purposes: an informative purpose and an organizational one. Borah [9] studied the presidential election in the U.S. using content analysis of the FB messages of three candidates. He found different categories: political advertising, emotional appeals, and social endorsement during two different elections-2008 and 2012.

Digital Government: Research and Practice, Vol. 1, No. 2, Article 12. Publication date: April 2020. 
Puentes-Rivera, Rúas-Araújo, and Dapena-González report on the importance of Facebook discussions during elections. They studied the Facebook accounts of the two main political parties in Spain during the general elections in 2016 by using eye-tracking on 24 student participants [35]. This research found elements of concentrated attention when reading political messages on the social media platform. A profound study of a Facebook discussion on environmental topics by Hendriks and colleagues shows that this platform seems personal and multi-sensorial, provoking more engagement and commitment. However, the potential to become a bridge that joins opposing viewpoints is limited, according to this study [26]. Babaoglu and Akman report the use of Facebook in municipalities in Turkey by studying the effectiveness of Facebook platforms in terms of the social media-citizen relationship [2].

In sum, from the electoral perspective, Facebook has different uses [17]. The first one is to provide a new communication channel for supporters; the second is to have a closer and friendlier tool for organization, supporting groups, and marketing to target audiences [24, 27]. Third, Facebook is used to send messages to opponents, disqualifying or attacking them. These different uses of Facebook relate to two aspects: political engagement and vote decision $[15,42]$. The main goal of the use of social media by campaigners is to convince the electorate to vote for them. For this reason, politicians use them to interact, promote, and spread the word about their election campaign. This point motivates our study of this phenomenon and clarifies the use of social media in political campaigns.

\subsection{Sentiment Analysis}

This investigation aims to understand the use of the emoticons/emojis/reactions in responding to Facebook posts regarding political campaigns. Several scholars have studied this issue recently. Lo [32] introduced the concept that users use emoticons/reactions to embellish their communications. The researchers found that emoticons/reactions are used as quasi-nonverbal cues for communication; for example, describing political emotions about candidates. Also, Chen [14] found that age, gender, and location have a bearing on the patterns of usage and interpretation of emoticons/reactions. The use of emoticons/reactions does not replace face-to-face interaction.

The use of social media for political campaigns draws on different studies that support either a positive correlation or a negative correlation. Bossetta and colleagues [10] found comparatively low levels of commenting on the official Brexit referendum campaigns vis-à-vis the media and a positive correlation between political interest and online participation on Facebook. However, a reverse spillover occurred immediately around and after the vote [10]. Also, Sampietro found that Facebook posts in Spanish politics in 2014 showed more positive emotions/reactions published by the political party and more negative emotions/reactions when they were replied to by users [37]. Research from Barclay [4] and colleagues confirms the traditional use of sentiment analysis based on positive, negative, and neutral scores. They studied the U.S. presidential election of 2012 and found that "sentiments are a reflection of the prevailing public mood," but these researchers only used these three categories.

Vitak and colleagues [49] support the negative relation, finding that young people use social media, and their political participation is complexly related to their social media usage. While young users may be participating in online political activities, the degree of this participation is somewhat superficial. Stier and colleagues [41] analyzed the populist messages on Facebook in Germany [41], which were posted by the Pegida right-wing movement; they found that little attention was given to their discourse on these platforms. The use of mainstream platforms appears to be the realm of the mainstream party system, which uses this kind of message. Another study from Groshek and Koc-Michalska [23] regarding the U.S. presidential election in 2016 found that: "Differing forms of active, passive, and uncivil social media were taken into account and the findings suggest active social media use for politics was actually related to less support for Republican populists, such as Trump, but that forms of both passive or uncivil social media use were linked to an increase in the likelihood of support to a level roughly equivalent to that of the traditional television viewing. These patterns are almost the inverse of support for Democratic populists, in this case namely Sanders." This means that the level of support comes from social media users and television viewers in equal measure [23, 41]. 
Table 1. Description of Facebook Reactions

\begin{tabular}{|c|c|c|}
\hline Reaction & Description & Expression \\
\hline Likes & Facebook user shows pleasure towards the post & Positive \\
\hline Love & Facebook user shows a lot of sympathy towards the post & Very positive \\
\hline Haha & Facebook user shows sarcasm, liking, laughter, but the feeling is not clear & Defined by the polarity \\
\hline Wow & Facebook user shows surprise (positive or negative) & Defined by the polarity \\
\hline Sad & Facebook is disappointed by the post & Negative \\
\hline Angry & Facebook user is completely at odds with the post & Very negative \\
\hline
\end{tabular}

Similar research by Samuel-Azran and colleagues [38] studied the Israel election in 2013 by analyzing the responses generated by negative messages attacking two different parties. This study reported a first mapping of the effects of a negative online campaign, using the relevance of political and religious context in a multiparty system [38]. Taking populist and negative discourse as the focus of his study, Kramer [30] analyzed the online discourse of leaders and citizens, justifying the exclusion of outgroups, the conceptual elaboration of right-wing populist ideology, and the development of a right-wing populist lifestyle and identity. Both studies contributed to the discussion that negative messages have different impacts on the elections. Vashisht and Thakur [47] report that Facebook emoticons/reactions identify positive and negative feelings based on an assessment of 1,250 Facebook statuses and 2,050 Facebook comments. These investigations link the use of symbols made by means of typography and not the reactions currently available on Facebook. There is a strong link between emotions such as depression, anxiety, and stress and the typography-generated emoticons used in Facebook posts and on Facebook profiles [40]. Hudson and colleagues [28] found a relationship between jealousy and emoticons.

Research from Bene [5] reports on interactions between candidates and Facebook followers. He also found that citizens are highly reactive to negative-emotion-filled, text-using, and activity-demanding posts and that virality is facilitated by memes and videos. However, Heiss's [25] research constitutes three important contributions to our research: (1) The use of an official fan profile and party vote share were negatively related to political actors' reactions to user comments; (2) Party profiles were least successful in stimulating user engagement; and (3) We found that post level, reasoning, post length, and references to competitive political actors have the potential to increase different types of user engagement.

In sum, we want to contribute to the idea that emoticons/reactions are important for our understanding of the different kinds of emotions users felt during the local government election in 2017.

\section{METHODS}

The introduction of emoticons/reactions to Facebook has recently been studied but has not been supported by empirical evidence [43]. For this reason, we developed our methods to measure positive and negative sentiments on Facebook (see Table 1). This is presented in the first part of this section, and we combined these methods with the $\mathrm{Oh}$ and Kumar sentiment index used during the U.S. presidential elections in 2016 [33]. This way, it is possible to understand the sentiment provoked by politicians in FB users and to compare the impact generated by candidates. This section is divided into three subsections: (1) sample description, (2) sentiment impact percentage, and (3) sentiment index description.

\subsection{Sample}

We collected data from the Facebook accounts of political parties involved in the state election. We did not consider other accounts other than the official political party ones. We downloaded the Facebook posts of the candidates standing for election, nominated by the following political parties: MORENA, PAN, PRD, and PRI. These four political parties were chosen because they were the most important ones in the previous political

Digital Government: Research and Practice, Vol. 1, No. 2, Article 12. Publication date: April 2020. 
Table 2. Facebook Posts and Reactions

\begin{tabular}{lrrrrr}
\hline Party & MORENA & \multicolumn{1}{c}{ PAN } & \multicolumn{1}{c}{ PRD } & \multicolumn{1}{c}{ PRI } & \multicolumn{1}{c}{ Total } \\
\hline Posts & 113 & 1059 & 602 & 2354 & $4,128.00$ \\
Comments & 120,838 & 280,139 & 92,734 & 292,882 & $786,593.00$ \\
Shares & 568,387 & 269,558 & 202,916 & 382,552 & $1,423,413.00$ \\
Likes & $1,301,998$ & $1,398,091$ & 657,873 & $1,332,664$ & $4,690,626.00$ \\
Love & 147,661 & 80,281 & 110,479 & 185,698 & $524,119.00$ \\
Haha & 57,909 & 406,523 & 20,539 & 205,428 & $690,299.00$ \\
Wow & 11,978 & 12,744 & 8,104 & 17,722 & $50,548.00$ \\
Sad & 1,924 & 4,312 & 901 & 3,876 & $11,013.00$ \\
Angry & 22,984 & 67,796 & 3,241 & 186,667 & $280,688.00$ \\
\hline
\end{tabular}

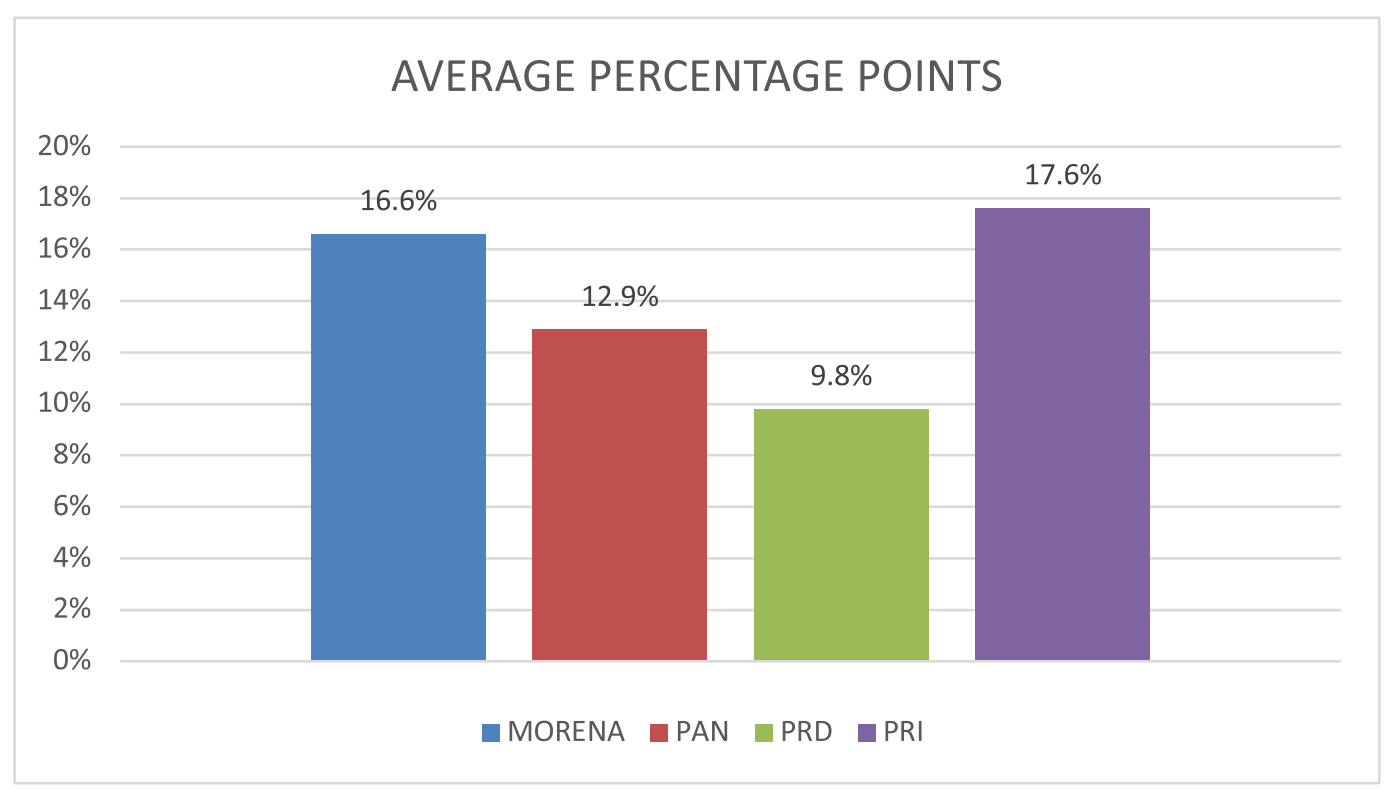

Fig. 1. Support for political parties in terms of percentage.

elections in the State of Mexico held on July 3rd, 2017. The period we selected for the analysis represents the three most important months before the election: March, April, May 2017.

We collected 113 posts from MORENA, 1,059 posts from PAN, 602 posts from PRD, and 2,358 posts from PRI (see Table 2), because that was the number of available posts on Facebook. In total, we analyzed 4,128 posts and evaluated the reactions posted on each post.

According to the results of polling companies during the study period, PRI was the highest positioned political party; in second place was MORENA, in third place was PAN, and in fourth place was PRD (see Figure 1). Figure 1 shows the average percentage points granted by the polling companies concerning the position of the political parties in terms of electoral preferences during March, April, and May 2017.

\subsection{Sentiment Impact Percentage}

The first step in assessing sentiments was to classify expressions as positive or negative. Facebook emojis/reactions have three kinds of emotions, as identified in emotional models by Ekman [20] and Plutchik [34]. 
Some of the emotions are positive ("Love" and "Like"), others negative ("Angry" and "Sad"), and some are neutral or do not have a clear polarization, because they depend on the post and provoked sentiment ("Haha" and "Wow").

Facebook users react by "liking" a post when they agree with it or when the post makes them feel positive. However, the "Love" reaction is used when Facebook users feel a very strong positive sentiment. The "Love" reaction is indicative of a stronger positive expression toward a post and, therefore, is more polarized than a "Like" reaction. For this reason, in this research, one "Love" reaction is considered to be twice as strong as a "Like" reaction. The purpose of this is to give more importance to a "Love" reaction than a "Like" reaction and to make a more precise calculation of positive polarity on Facebook.

It is the same calculation with the "Sad" and "Angry" buttons, since a post that causes negative sentiments generates these two emotions; an "Angry" expression represents a stronger negative emotion in the polarization than a "Sad" one. For this reason, an "Angry" expression is graded as being twice as strong a reaction as a "Sad" one in the polarization scale for the calculations in this research.

The "Haha" and "Wow" buttons are not considered as having a defined polarity, since the "Haha" expression can be indicative of joy (positive emotion) or sarcasm (negative emotion) depending on the post content and the number of "Like," "Love," "Sad," and "Angry" emojis/reactions. A post that gets mostly positive emojis ("Like" and "Love") also gets a higher number of "Haha" emojis, indicating joy for the content of the post. However, if the post has mostly negative emojis ("Sad" and "Angry") and gets "Haha" emojis, this indicates sarcasm and, consequently, negative polarity. A "Wow" (surprised expression) can be generated by positive or negative sentiments. So, the polarity of this type of emotion may be neutral, but it usually falls into the prevailing predominant polarity. In the analysis, we noticed that the "Wow" emojis/reactions are indicative of a positive expression (positive surprise), since they predominated in the posts with more "Like" and "Love" expressions. On the contrary, "Haha" expressions have a negative intention (sarcasm), since most of the expressions obtained in those Facebook posts were "Sad" and "Angry." This is explained by the fact that the emoji/reactions can express surprise ("Wow" emoji) at an event that is perceived as negative or positive, depending on the context and type of Facebook post.

In our data, most reactions on the posts of each candidate were positive. For that reason, we classified this kind of expression as positive. In regard to the "Haha" emoji, sarcasm is generally shown, indicating that Facebook users mock the post made by the political candidate. We evaluated this type of expression as negative. Thus, we calculated the total positive sentiment for data as:

$$
\text { TotalPositiveSentiment }=\text { Wow }+ \text { Likes }+2 \cdot \text { Love }
$$

and the total negative sentiment as:

$$
\text { TotalNegativeSentiment }=\text { Haha }+ \text { Sad }+2 \cdot \text { Angry }
$$

With these two formulas, we were able to calculate the sentiment polarity (positive or negative) for each candidate in terms of their Facebook posts. The political party with the most posts was PRI, followed by PAN in second place, then PRD, and the political party that posted the least was MORENA. However, the number of "like" reactions/expressions was very similar for PRI, PAN, and MORENA. Nevertheless, there were also differences among other expressions. The political party that obtained the most "Love" expressions/reactions was PRI. Although MORENA was the political party with the fewest publications, it had the second highest number of "love" reactions. This means that MORENA generated a more positive response from its followers, despite not posting as much as the PRI. It should be noted that the two parties with the most "Haha" expressions were PAN and PRI, which means that several of their posts generated mockery or sarcasm.

Moreover, they were the political parties with the most negative expressions ("Sad" and "Angry"). One aspect that is important to note is that MORENA's posts were the most often shared. As it was the party with the fewest posts, each one had the greatest impact on the political campaign. The result of calculating total positive and negative sentiments is shown in Table 3.

Digital Government: Research and Practice, Vol. 1, No. 2, Article 12. Publication date: April 2020. 
Table 3. Total Positive and Negative Sentiment

\begin{tabular}{lcc}
\hline Political party & Total Positive Sentiment & Total Negative Sentiment \\
\hline MORENA & $1,609,298$ & 105,801 \\
PAN & $1,561,397$ & 546,427 \\
PRD & 886,935 & 27,922 \\
PRI & $1,721,782$ & 582,638 \\
Total & $5,789,412$ & $1,262,788$ \\
\hline
\end{tabular}

Table 4. Percentage Impact of Facebook Comments and Reactions

\begin{tabular}{lcccc}
\hline Impact & Impact of Content & $\begin{array}{c}\text { Impact of Number } \\
\text { of times shared }\end{array}$ & $\begin{array}{c}\text { Percentage Impact } \\
\text { of Comments }\end{array}$ & $\begin{array}{c}\text { Impact of Number } \\
\text { of Times Shared }\end{array}$ \\
\hline MORENA & $1,069.36$ & $5,029.97$ & $66.32 \%$ & $86.96 \%$ \\
PAN & 264.53 & 254.54 & $16.41 \%$ & $4.40 \%$ \\
PRD & 154.04 & 337.07 & $9.55 \%$ & $5.83 \%$ \\
PRI & 124.42 & 162.51 & $7.71 \%$ & $2.81 \%$ \\
Total Impact & $1,612.36$ & $5,784.09$ & $100.00 \%$ & $100.00 \%$ \\
\hline
\end{tabular}

To measure the impact of comments on and shares of the posts of the candidates, we calculated a total percentage. Calculating percentages allows us to compare different values on the same scale. For this reason, we calculated the percentage and based our analysis on this calculation. First, we calculated the impact of comments on and shares of posts, and then we calculated the percentage to understand the impact of Facebook on each political party.

We calculated the impact related to shares (impact of number of times shared) as the total number of shares divided among the total number of posts (shares/posts); and the impact related to comments (impact of comments) as the total number of comments divided among the total number of posts (comments/posts). Then, we calculated the percentage impact of comments as the total impact (of each political party)/the total impact of comments. We calculated the percentage impact of number of times shared in the following way: impact of number of times shared (pertaining to each political party)/the total impact of number of times shared. The results of these calculations are presented in Table 4.

In this way, we show the impact of comments and shares depending on the number of posts. MORENA had the highest impact, although it is the political party with fewest posts. However, PRI has the least favorable impact percentage, although it is the political party with most posts.

\subsection{Sentiment Index}

To measure the sentiment of Facebook users toward each political party, we used the Oh and Kumar Sentiment Index to find the overall sentiment toward Facebook posts [33]. The sentiment index logarithm shows the relationship between negative and positive posts. The value obtained is a number that indicates how positive or negative sentiments generated by followers of social media are:

$$
\text { Sentiment Index }=\ln \left\lfloor\frac{1+\text { TOTAL }}{1+\text { TOTAL } L^{\text {NEGATIVE }}}\right\rfloor .
$$

This way, we measured the impact of posts by political parties and the sentiment of Facebook users toward each political party during the political campaign.

Digital Government: Research and Practice, Vol. 1, No. 2, Article 12. Publication date: April 2020. 


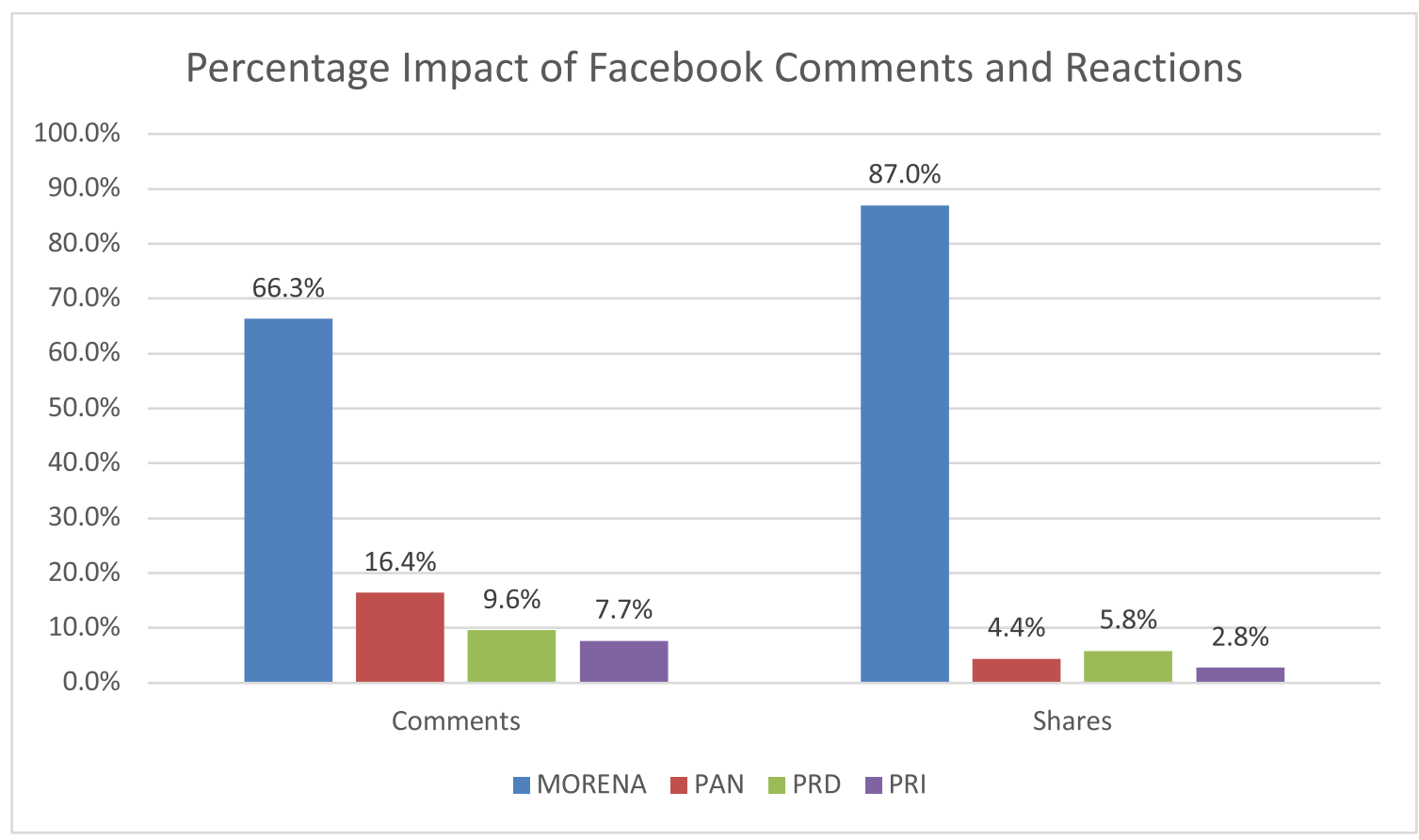

Fig. 2. Facebook comments in Governor's election of the State of Mexico.

\section{FINDINGS}

The purpose of this section is to describe our findings according to the proposed sentiment analysis methodology. In this first section, we report on the impact of Facebook posts calculated by way of the formula described in the method section. The second part reports on sentiment analysis totals; the third part reports on positive sentiment; and finally, the last part reports on the negative sentiment found in this research.

According to our objective and methods, we use emojis/reactions to calculate the sentiment index and then compare this value for the different candidates running for election.

\subsection{The Impact of Facebook Posts}

The impact percentage of number of times shared and commented represents the number of times each Facebook post was shared or commented on. According to our data, MORENA's posts were the most shared and commented upon in our sample. We found that posts from this political party were the most disseminated by Facebook users. Figure 2 represents this outcome. Although there are more PRI posts compared to the other political parties, PRI posts had the lowest impact (see Figure 2). MORENA's impact based on shares and comments was higher than that of the other political parties. This could be explained-but not tested-based on two reasons: the first one is a coordinated social-media strategy, and second, because MORENA had the support of more followers than the other parties did.

Using the Sentiment Index based on positive vs. negative posts [33], our results are as follows: although MORENA had the highest impact percentage in terms of shares and comments, PRI was the political party with most posts, and PRD had the highest sentiment index (see Figure 3). In other words, PRD was the political party able to generate the largest impact by using Facebook (3.46), then MORENA (2.72), PRI (1.08), and PAN (1.06). PRI had the most Facebook posts; however, it had the second most negative sentiment. This is because PRI posts were not shared and commented upon at the same level as PRD posts, and most PRI posts generated expressions 


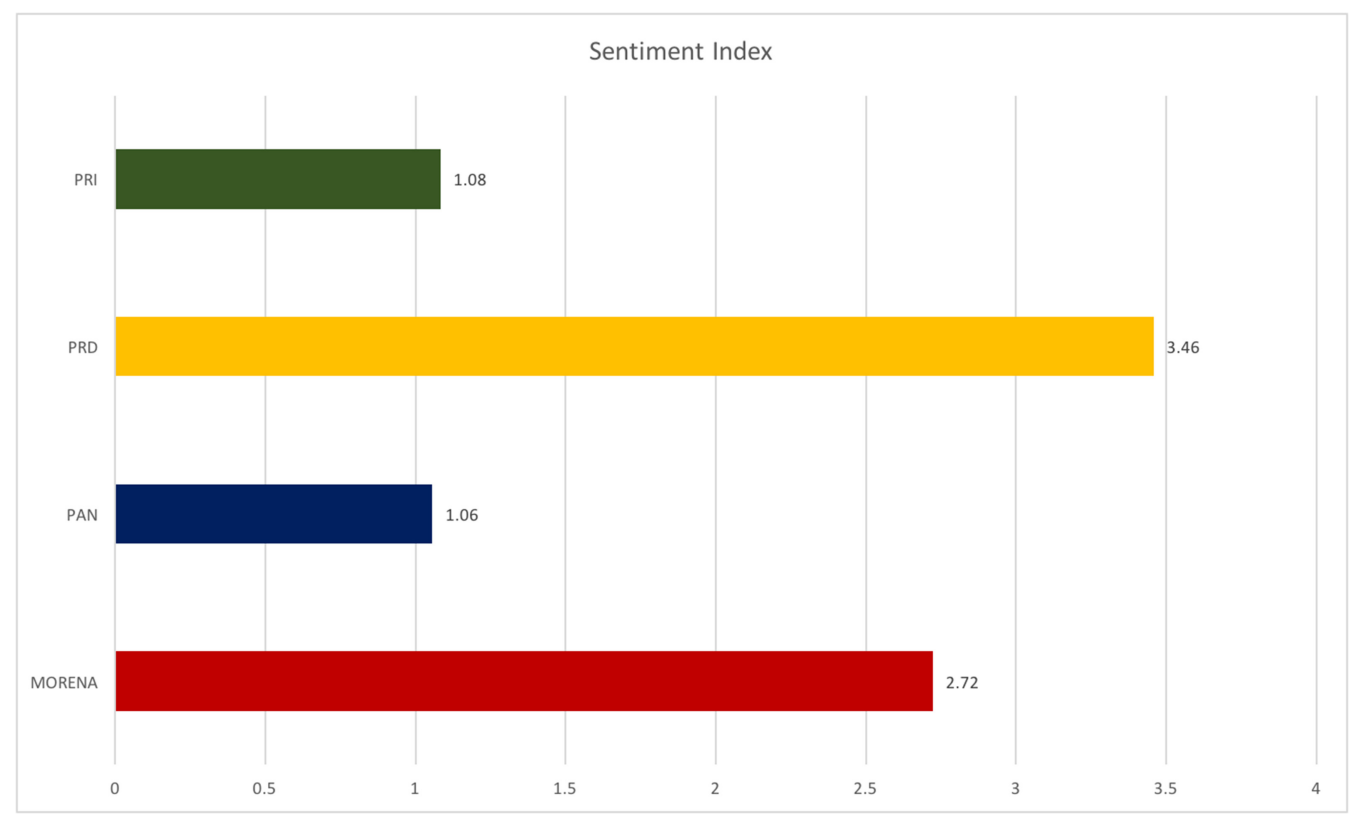

Fig. 3. Sentiment index in the Governor's election of the State of Mexico.

Table 5. Sentiment Index vs. Election Result

\begin{tabular}{lcc}
\hline Impact & Sentiment Index & Election result \\
\hline PRI & 1.08 & $33.72 \%$ \\
MORENA & 2.72 & $30.81 \%$ \\
PRD & 3.46 & $17.79 \%$ \\
PAN & 1.06 & $11.28 \%$ \\
\hline
\end{tabular}

of mockery or anger. PRI had the highest level of total negative sentiment. Although MORENA had few posts, its Facebook impact was the second highest.

Contrary to our analysis based on the sentiment index, PRI was the political party that won the elections (see Table 5). So, we can assume that the sentiment analysis of Facebook does not reflect voter behavior [10, 49]. Most PRI voters live in the poorest areas of the State of Mexico, where Facebook is not accessible. Most PRI voters do not have access to FB, but followers of other parties do. For this reason, the sentiment obtained by the PRI is low compared with other political parties, as there were more FB followers supporting parties other than the PRI.

\section{DISCUSSION}

This is the first study of the use of Facebook emoticons/reactions to assess elections in Mexico. Because of this, three assumptions must be considered to understand these results. The first assumption is that emotions and feelings are part of all contemporary elections [11, 16, 21]. Nevertheless, few studies have focused on the impact of emotions expressed on social media, particularly in electoral contexts. As stated in the literature review, more research has been done on the electoral impact, political efficacy of information, and users' decisions or expectations, but until now, assessing emotions using these new tools-emoticons/reactions-has not been done.

Our results are ambiguous. If the political party with most reactions to their posts-positive or negativewon the election, our hypothesis would be supported: The use of Facebook would create a positive context 
that promoted users' choice in favor of this political party. However, the political context of Mexican elections (especially in the State of Mexico) has been documented, and other factors such as corruption, difficulty of voting, apathy and disinterest on part of the voters, and clientelism undermine voters' free will in favor of the ruling political party $[29,31,39]$.

Our second assumption is that the sentiment analysis of Facebook emoticons/reactions will reflect the emotions of users but not their intention to vote. As can be seen in Table 5, the election result does not relate to the calculated sentiment index. However, the sentiment index represents the perception of Facebook users toward each candidate. For this election, emoticons/reactions shown in Facebook posts and the results of elections do not correlate $(\mathrm{r}=-0.025)$. This conclusion is based on counting the sentiments indicated for each post. For this reason, our first hypothesis is not supported. The third assumption is that users of social media in the State of Mexico interact impulsively toward political candidates and react spontaneously when posting their reactions on Facebook.

Results from this election in the State of Mexico indicate that the winning party-the incumbent PRI-received mockery and anger from citizens; this is supported by previous research [37, 41]. The opposition party, MORENA had more user interaction and sharing of posts and received a balanced number of positive and negative comments, which created the perception of MORENA becoming the winning party. Nonetheless, this party came in second place in spite of social-media engagement with a very large number of users.

The PRD came in third place despite having the highest sentiment index value, and therefore, the highest positive sentiment expressed by Facebook users. This result is grounded in both assumptions. The number of posts from the PRD political party is fewer than the other two political parties (PAN and PRI). Even the small number of posts and interactions attracted more users to share them due to the quality of information disseminated and the kind of information spread in the mass media. The PRD candidate had an image that attracted the majority of young users, who interact the most on social networks. So, this kind of issue may explain the increase in positive sentiment. This is consistent with research by Kramer [30], who analyzed online discourse and the exclusion of groups. The PRD and MORENA's discourse could create some exclusion of PRI or PAN supporters, however, this must be validated in further research. If sentiments influenced users' decisions, the MORENA party should have won the election.

This research project has several limitations: the first one is that Facebook users could lie about the emotions they felt during the political campaign and expressed these same emotions untruthfully. Reactions to Facebook posts could be superficial and not be a true reflection of voter behavior. It is not clear yet whether emoticons/reactions reflect the actual views of users. Some users may be angry about aspects related to the political campaign, such as news, candidates, and political communications. Some users react impulsively and that may influence the emoticons/reactions that each political party receives. There is no research on single users or individual posts. So, the combination of several users trying to build or destroy the image of a political candidate could be represented by this measurement instead of sentiment analysis. The second limitation is the use of bots to modify the number of users, likes, or hits on each candidate. Social media has the advantage of having huge potential for communication, but also the disadvantage of disseminating fake news or information that is not generated by human users. A third limitation is the set of contextual factors. We are aware that contextual factors, such as the digital divide, digital culture, the political preferences of voters, and political parties' backgrounds, influence voters' decisions and sentiments. Future research could explore the different effects of contextual factors and social media.

\section{CONCLUSIONS}

Our sentiment analysis expands understanding of elections in the State of Mexico, because it increases our understanding of the range and diversity of emotions of the users expressed by way of Facebook emoticons/reactions. Previous research classified basic feelings into three types: positive, negative, and neutral. Our research also confirms the sentiment index model proposed by Oh and Kumar [33], providing evidence and supporting the

Digital Government: Research and Practice, Vol. 1, No. 2, Article 12. Publication date: April 2020. 
reliability of this model [12, 13, 45, 48]. Our investigation answered the research question: Did the Facebook reactions of users in Mexico reflect the outcomes of the elections and possibly also the users' emotions towards the political candidates of the State of Mexico in 2017?

Our first hypothesis is partially supported, because there is evidence that the party with the highest positive sentiment score (PRD) increased their votes in the election to reach third place in the race. This is possibly due to the influence of comments on social media. Facebook emoticons/reactions reflect users' emotions toward the candidate but did not reflect voter decisions. Accordingly, we reject our second hypothesis, because the sentiment of users-reflected by emoticons/reactions-did not relate to the electoral outcome. Our findings reveal that the political party with the highest positive sentiment index (PRD) did not win the election; neither did the party that had the most reactions to their posts (MORENA). This outcome must be analyzed in future research to consider different contextual factors that explain both findings more comprehensively. It is also important to consider that the majority of the voters for the winning party were disadvantaged people from low-income households, who are marginalized and, for years, have voted for the PRI.

A complementary finding of the investigation shows that the diffusion of the information by FB users was greater for the MORENA party. This points out that MORENA's Facebook account strategies were more effective than those of the other political parties. The winner of the electoral race, PRI, was the political party with most posts but with the lowest level of information dissemination. The political party with the highest positive sentiment was PRD. These findings open up the possibility of several future research paths in this field. The next step of this study is to analyze the content of MORENA and PRD's posts that had both high positive sentiment and influential comments. A second future step is to compare the influence of the combined perspectives of social media such as Twitter, Instagram, and Facebook in a political campaign. A third step is to improve our methods. We have new tools from artificial intelligence that allow more accuracy and different perspectives that point to a better understanding of this topic. This investigation aimed to assess sentiment analysis in political campaigns as an indication of the mood of users expressed through Facebook emoticons/reactions. We hope that this pioneering study in Mexico can foster more research in this area and consider emotions expressed through emoticons/reactions on Facebook as a way of assessing voter behavior.

\section{REFERENCES}

[1] Kim Normann Andersen and Rony Medaglia. 2009. The use of Facebook in national election campaigns: Politics as usual? In Proceedings of the International Conference on Electronic Participation. Springer, Berlin, 101-111.

[2] Cenay Babaoglu and Elvettin Akman. 2018. Participation with social media: The case of Turkish metropolitan municipalities in Facebook. In Optimizing E-Participation Initiatives through Social Media. IGI Global, Hershey, PA, 77-102.

[3] Lázaro M Bacallao-Pino. 2016. Redes sociales, acción colectiva y elecciones: Los usos de Facebook por el movimiento estudiantil chileno durante la campaña electoral de 2013. Palab. Clave 19, 3 (2016), 810-837.

[4] Francis P. Barclay, Pichandy Chinnasamy, and Priyadarshni Pichandy. 2014. Political opinion expressed in social media and election outcomes-US presidential elections 2012. f. Media Commun. 1, 2 (2014), 15-22.

[5] Márton Bene. 2017. Go viral on the Facebook! Interactions between candidates and followers on Facebook during the Hungarian general election campaign of 2014. Inf. Commun. Soc. 20, 4 (2017), 513-529.

[6] Bruce Bimber. 1998. The internet and political transformation: Populism, community, and accelerated pluralism. Polity 31, 1 (1998), 133-160.

[7] Bruce Bimber and Lauren Copeland. 2013. Digital media and traditional political participation over time in the US. f. Inf. Technol. Polit. 10, 2 (2013), 125-137.

[8] Leticia Bode. 2012. Facebooking it to the polls: A study in online social networking and political behavior. F. Inf. Techno. Polit. 9, 4 (2012), 352-369.

[9] Porismita Borah. 2016. Political Facebook use: Campaign strategies used in 2008 and 2012 presidential elections. F. Inf. Technol. Polit. 13, 4 (2016), 326-338.

[10] Michael Bossetta, Anamaria Dutceac Segesten, and Hans-Jörg Trenz. 2018. Political participation on Facebook during Brexit. f. Lang. Polit. 17, 2 (2018), 173-194.

[11] Eva Campos-Domínguez and Política Neamp. 2017. Twitter and political communication. Prof. Inf. 26, 5 (2017), 785-794. DOI: https://doi.org/10.3145/epi.2017.sep.01

Digital Government: Research and Practice, Vol. 1, No. 2, Article 12. Publication date: April 2020. 
[12] Juliet E. Carlisle and Robert C. Patton. 2013. Is social media changing how we understand political engagement? An analysis of Facebook and the 2008 presidential election. Polit. Res. Q. 66, 4 (2013), 883-895. DOI : https://doi.org/10.1177/1065912913482758

[13] Andrea Ceron, Luigi Curini, Stefano M. Iacus, and Giuseppe Porro. 2014. Every tweet counts? How sentiment analysis of social media can improve our knowledge of citizens' political preferences with an application to Italy and France. New Media Soc. 16, 2 (2014), 340-358.

[14] Amanda Chen Yuet Wei. 2012. Emoticons and the Non-verbal Communication: With Reference to Facebook. Ph.D. Dissertation. Christ University.

[15] Meredith Conroy, Jessica T. Feezell, and Mario Guerrero. 2012. Facebook and political engagement: A study of online political group membership and offline political engagement. Comput. Hum. Behav. 28, 5 (2012), 1535-1546.

[16] Catherine Corrigall-Brown and Rima Wilkes. 2014. Media exposure and the engaged citizen: How the media shape political participation. Soc. Sci. F. 51, 3 (2014), 408-421. DOI : https://doi.org/10.1016/j.soscij.2014.03.009

[17] Daniela V. Dimitrova and Dianne Bystrom. 2013. The effects of social media on political participation and candidate image evaluations in the 2012 Iowa Caucuses. Amer. Behav. Sci. 57, 11 (2013), 1568-1583.

[18] Daniela V. Dimitrova, Adam Shehata, Jesper Strömbäck, and Lars W. Nord. 2014. The effects of digital media on political knowledge and participation in election campaigns: Evidence from panel data. Commun. Res. 41, 1 (2014), 95-118.

[19] Robin Effing, Jos van Hillegersberg, and Theo Huibers. 2016. Social media indicator and local elections in the Netherlands: Towards a framework for evaluating the influence of Twitter, YouTube, and Facebook. In Social Media and Local Governments. Springer, Cham, 281-298.

[20] Paul Ekman. 1993. Facial expression and emotion. Amer. Psychol. 48, 4 (1993), 384.

[21] Sandra González-Bailón, Rafael E. Banchs, and Andreas Kaltenbrunner. 2011. Emotions, public opinion and U.S. presidential approval rates: A 5 year analysis of online political discussions. Hum. Commun. Res. 38, 2 (2011), 121-143. Retrieved from http://papers.ssrn. com/abstract=1964623 http://papers.ssrn.com/sol3/papers.cfm?abstract \{_\}id=1964623.

[22] Sandra González-Bailón, Javier Borge-Holthoefer, Alejandro Rivero, and Yamir Moreno. 2011. The dynamics of protest recruitment through an online network. Sci. Rep. 1 (2011), 197.

[23] Jacob Groshek and Karolina Koc-Michalska. 2017. Helping populism win? Social media use, filter bubbles, and support for populist presidential candidates in the 2016 US election campaign. Inf. Commun. Soc. 20, 9 (2017), 1389-1407.

[24] Stevan Harnad. 2011. Politician 2.0 on Facebook: Information behavior and dissemination on social networking sites-Gaps and bestpractice. Evaluation results of a novel eParticipation toolbox to let politicians engage with citizens online. FeDEM efourn. eDemoc. Open Gov. 3 (2011), 33-41. Retrieved from http://www.jedem.org/article/view/78.

[25] Raffael Heiss, Desiree Schmuck, and Jörg Matthes. 2019. What drives interaction in political actors' Facebook posts? Profile and content predictors of user engagement and political actors' reactions. Inf. Commun. Soc. 22, 10 (2019), 1497-1513.

[26] Carolyn M. Hendriks, Sonya Duus, and Selen A. Ercan. 2016. Performing politics on social media: The dramaturgy of an environmental controversy on Facebook. Envir. Polit. 25, 6 (2016), 1102-1125.

[27] Sounman Hong and Daniel Nadler. 2012. Which candidates do the public discuss online in an election campaign?: The use of social media by 2012 presidential candidates and its impact on candidate salience. Gov. Inf. Q. 29, 4 (2012), 455-461. Retrieved from http:// www.sciencedirect.com/science/article/pii/S0740624X12000895.

[28] Michael B. Hudson, Sylis C. Nicolas, Molly E. Howser, Kristen E. Lipsett, Ian W. Robinson, Laura J. Pope, Abigail F. Hobby, and Denise R. Friedman. 2015. Examining how gender and emoticons influence Facebook jealousy. Cyberpsych. Behav. Soc. Netw. 18, 2 (2015), 87-92.

[29] José María Infante. 2005. Elecciones en México: Restricciones, fraudes y conflictos. Confin. Relac. Int. y Cienc. Polít. 1, 2 (2005), 65-78. Retrieved from http://www.redalyc.org/articulo.oa?id=63310205.

[30] Benjamin Krämer. 2017. Populist online practices: The function of the Internet in right-wing populism. Inf. Commun. Soc. 20, 9 (2017), 1293-1309.

[31] Nina Lakhani. 2017. Mexico State Election Heads to Court amid Alleged Intimidation and Vote-buying. Retrieved from https://www. theguardian.com/world/2017/jun/05/mexico-state-election-court-alfredo-del-mazo-maza-delfina-gomez.

[32] Shao-Kang Lo. 2008. The nonverbal communication functions of emoticons in computer-mediated communication. CyberPsych. Behav. 11, 5 (2008), 595-597.

[33] Chong Oh and Savan Kumar. 2017. How Trump won: The role of social media sentiment in political elections. In Proceedings of the Pacific Asia Conference on Information Systems (PACIS'17). 48.

[34] Robert Plutchik. 1965. What is an emotion? J. Psych. 61, 2 (1965), 295-303.

[35] Iván Puentes-Rivera, José Rúas-Araújo, and Borja Dapena-González. 2017. Candidatos en Facebook: Del texto a la imagen. Anál. Activ. Aten. Vis. Rev. Díg. 1, 3 (2017), 51-94.

[36] Scott P. Robertson, Ravi K. Vatrapu, and Richard Medina. 2009. The social life of social networks: Facebook linkage patterns in the 2008 U.S. presidential election. On 10th Annual International Conference on Digital Government Research: Social Networks: Making Connections between Citizens, Data \& Government. Digital Government Society of North America, 6-15.

[37] Agnese Sampietro and Lidia Valera Ordaz. 2015. Emotional politics on Facebook. An exploratory study of Podemos' discourse during the European election campaign 2014. RECERCA. Rev. Pensa. Anàl. 17 (2015), 61-83.

Digital Government: Research and Practice, Vol. 1, No. 2, Article 12. Publication date: April 2020. 
[38] Tal Samuel-Azran, Moran Yarchi, and Gadi Wolfsfeld. 2017. Engagement and likeability of negative messages on Facebook during Israel's 2013 elections. F. Soc. Media Soc. 6, 1 (2017), 42-68. Retrieved from http://thejsms.org/index.php/TSMRI/article/view/231.

[39] Barbara Schroter. 2010. Clientelismo politico: Existe el fantasma y como se viste? Rev. Mex. Sociol. 72, 1 (2010), 141-175.

[40] Michele Settanni and Davide Marengo. 2015. Sharing feelings online: Studying emotional well-being via automated text analysis of Facebook posts. Front. Psych. 6 (2015), 1045.

[41] Sebastian Stier, Lisa Posch, Arnim Bleier, and Markus Strohmaier. 2017. When populists become popular: Comparing Facebook use by the right-wing movement Pegida and German political parties. Inf. Commun. Soc. 20, 9 (2017), 1365-1388.

[42] Gary Tang and Francis L. F. Lee. 2013. Facebook use and political participation: The impact of exposure to shared political information, connections with public political actors, and network structural heterogeneity. Soc. Sci. Comput. Rev. 31, 6 (2013), 763-773.

[43] Ye Tian, Thiago Galery, Giulio Dulcinati, Emilia Molimpakis, and Chao Sun. 2017. Facebook sentiment: Reactions and emojis. In Proceedings of the 5th International Workshop on Natural Language Processing for Social Media. Association for Computational Linguistics, $11-16$.

[44] Terri L. Towner. 2012. Campaigns and elections in a web 2.0 world: Uses, effects, and implications for democracy. In Web 2.0 Technologies and Democratic Governance. Springer, New York, NY, 185-199.

[45] Andranik Tumasjan, To Sprenger, Pg Sandner, and Im Welpe. 2010. Predicting elections with Twitter: What 140 characters reveal about political sentiment. In Proceedings of the 4th International AAAI Conference on Weblogs Social Media. Association for the Advancement of Artificial Intelligence, Washington, DC, 178-185. DOI : https://doi.org/10.1074/jbc.M501708200

[46] Andranik Tumasjan, Timm Oliver Sprenger, Philipp G. Sandner, and Isabell M. Welpe. 2010. Predicting elections with Twitter: What 140 characters reveal about political sentiment. In Proceedings of the 4th International AAAI Conference on Weblogs and Social Media 10, 1 (2010), 178-185.

[47] Geetika Vashisht and Sangharsh Thakur. 2014. Facebook as a corpus for emoticons-based sentiment analysis. Int. f. Emerg. Tech. Adv. Eng. 4 (2014), 904-908.

[48] Tapio Vepsäläinen, Hongxiu Li, and Reima Suomi. 2017. Facebook likes and public opinion: Predicting the 2015 Finnish parliamentary elections. Gov. Inf. Quart. 34, 3 (2017), 524-532.

[49] Jessica Vitak, Paul Zube, Andrew Smock, Caleb T. Carr, Nicole Ellison, and Cliff Lampe. 2011. It's complicated: Facebook users' political participation in the 2008 election. CyberPsych. Behav. Soc. Netw. 14, 3 (2011), 107-114.

Received February 2019; revised December 2019; accepted January 2020 